\title{
Article
}

\section{How useful is a single measurement of patellar mobility in the assessment of patients with patellofemoral pain?}

Janssen, Jessica, Dey, P, Celik, Canpolat, Richards, James and Selfe, Available at http://clok.uclan.ac.uk/24886/

Janssen, Jessica ORCID: 0000-0002-5961-2736, Dey, P, Celik, Canpolat, Richards, James ORCID: 0000-0002-4004-3115 and Selfe, J (2019) How useful is a single measurement of patellar mobility in the assessment of patients with patellofemoral pain? Physiotherapy Practice and Research, 40 (1). pp. 29-35. ISSN 2213-0683

It is advisable to refer to the publisher's version if you intend to cite from the work. http://dx.doi.org/10.3233/PPR-180122

For more information about UCLan's research in this area go to http://www.uclan.ac.uk/researchgroups/ and search for <name of research Group>.

For information about Research generally at UCLan please go to http://www.uclan.ac.uk/research/

All outputs in CLoK are protected by Intellectual Property Rights law, including Copyright law. Copyright, IPR and Moral Rights for the works on this site are retained by the individual authors and/or other copyright owners. Terms and conditions for use of this material are defined in the policies page. 
1 How useful is a single measurement of patellar mobility in the assessment of

2 patients with patellofemoral pain?

3

4 Jessie Janssen ${ }^{a}$, Paola Deyb, Canpolat Celik ${ }^{a}$, Jim Richards ${ }^{a}$, James Selfe.

5 a Allied Health Research unit, University of Central Lancashire, Preston, UK

$6{ }^{b}$ Faculty of Health and Social Care, Edge Hill University, Ormskirk, UK

7 c Department of Health Professions, Manchester Metropolitan University,

$8 \quad$ Manchester, UK

9

10 Corresponding author: Dr Jessie Janssen, BB204, Research Fellow (Physiotherapy),

11 Allied Health Research unit, University of Central Lancashire, UK, Preston.

$12+441772894560$, jianssen@uclan.ac.uk

Word count: 2460

15

Keywords:

- Patellofemoral Pain

- Patellar mobility

- Physiotherapy

- Subgroups

- Stratification 
Abstract

Introduction: Patellar mobility is often routinely assessed in people with patellofemoral pain (PFP) in clinical practice. This study assessed the stability of the data when measuring patellar mobility using the total medial-lateral patellar glide test across multiple repetitions. It also compared patellar mobility of people with healthy knees to people with PFP and within subgroups of PFP.

Methods: Twenty-two people without knee problems underwent five repetitions of the total medial-lateral patellar glide test. Differences in mean value for each repetition and the intra-class correlations (ICC) between the first assessment and the average values of additional repetitions were calculated. Mean patellar mobility was compared with 127 participants with PFP who took part in a previously published subgrouping study. Differences between the healthy knee group and PFP subgroups were also explored using a one-way ANOVA with pairwise comparisons.

Results: The mean patellar mobility in healthy individuals was $16.4 \mathrm{~mm}$ (SD 5.3), difference in mean patellar mobility across repetitions was minimal and the ICC ranged between 0.93 and 0.95 . People with PFP had significantly lower patellar mobility than the healthy knee group. Two of three PFP subgroups had statistically significantly lower mean patellar mobility (difference in mean $-5.6 \mathrm{~mm}$ and $-6.5 \mathrm{~mm}$; $\mathrm{P}<0.001)$.

Discussion: A single medial-lateral patellar glide test appears as informative as repeated tests in practice. One off measures of patellar mobility using the total medial-lateral patellar glide test may identify subgroups of PFP to help guide treatment in clinical practice. Further work is needed to assess other reliability parameters for this measure. 
- A one off measure of the total medial-lateral patellar mobility is as accurate as the average of multiple measures.

- There is a difference between healthy participants and people with PFP in total patellar mobility

- There is evidence of lower patella mobility as measured by a one off measure of the total medial lateral patellar mobility in some subgroups of PFP patients 
Patellofemoral pain (PFP) is a common disorder in younger adults. Despite it being seen by many as a trivial condition [1], over $90 \%$ of those presenting with the condition are still suffering four years after diagnosis [2-4]. There is an indication that participants could develop osteoarthritis at a later stage [3], however the link between PFP and osteoarthritis in later life is currently weak due to the limited evidence base [5].

Assessment of patellar mobility is common in clinical practice for patients suspected of having PFP. This is as one of the dominant theories for the aetiology of PFP has been malalignment and/or mal-tracking of the patella through the trochlear groove. This mal-tracking leads to reduced patellofemoral joint contact area which increases the load on that joint and, hence, may contribute to increased pain [6]. Consequently, many treatments for patellofemoral pain have focused on improving patellofemoral control, through, for example, proximal (hip abductors and quadriceps) strengthening and stretching exercises [7], patella mobilisations [8], patella taping [9]. Both hypomobility and hypermobility of the patella are considered to be clinically important. However, there has been increasing recognition that the aetiology of PFP is more complex and that there may be other mechanisms contributing to reduced patellofemoral joint contact area and/or elevated patellofemoral joint loading (Powers et al 2017). This has led to increased interest in identifying subgroups of patellofemoral pain so that treatment can be targeted more optimally and efficiently [10].

In a recently published subgrouping study (TIPPS), we identified three subgroups among 127 adults aged 18 to 40 years with PFP using six clinical tests routinely available in practice [11]. These subgroups included a 'weak and tight' (39\%) 
subgroup, a 'weak and pronated feet' (39\%) subgroup and a 'strong' (22\%) subgroup. One of the clinical tests used in TIPPS was the total medial-lateral patellar glide test. The mean patellar mobility using this test was similar in the 'weak and tight' subgroup and the 'strong' subgroup but it was significantly higher in the 'weak and pronated' subgroup [11]. One difficulty in interpreting this data clinically was the limited published data on normative means, standard deviations or ranges. Studies that had been published had either been in adolescents only [12], had used different methods to measure patellar mobility [13], or used methods that could not be repeated in routine practice $[14,15]$.

From the literature, it was also unclear how many measurements were needed for an accurate assessment. In the TIPPS study, only one measurement of patellar mobility using the lateral-medial patellar glide test was taken; this is in line with routine clinical practice. This is because the method involves making a mark on the knee with a pen. However, others have also repeated the patellar mobility measurement three times $[13,14]$. This is also usual practice for many of the other clinical tests used in the TIPPS study and in clinical practice, such as measuring quadriceps strength, which involves taking the average of three measurements to achieve stable values [11].

Therefore, in this study, we examined the stability of the data from the medial-lateral patellar glide test across sequential measurements. Additionally, we aimed to measure patellar mobility in a group of young adults without a recent history of knee pain, to provide data for comparison with that of patellofemoral pain patients [11]. 
104 This study was approved by the University of Central Lancashire ethics committee (Science Technology, Engineering, Medicine and Health (STEMH) project number 355).

107

\section{Participants}

Twenty-three participants were recruited through advertising across the University and through word of mouth. Participants were aged between 18 and 40 years without current neurological or musculoskeletal disorders, knee pain or history of surgery to the lower extremities. Informed written consent was obtained. We were unable to fully test one participant in this study as they were hyper-sensitive to the patellae being touched, but a complete dataset was available for the remaining 22 participants.

The comparison data consisted of 127 patients with patellofemoral pain who were included in the TIPPS subgrouping study. These patients were aged between 18 and 40 years and diagnosed with non-specific unilateral or bilateral PFP. Detailed information about these patients can be found in Selfe et al 2016.

\section{Procedure}

All participants were asked to attend one testing session at a University Physiotherapy clinic, where first the participant's age, gender, height and weight were recorded. One researcher, a trained physiotherapist, performed the total medial-lateral patellar glide test. The participant lay in a supine position with the quadriceps relaxed and knees extended. After a verbal explanation of the test, the 
researcher applied a medially directed force to the lateral border of the patella with the thumbs and the maximum displacement of the inferior pole of the patella was marked on the skin with a piece of tape. This was followed by a laterally directed force to the medial border of the patella and again the maximum displacement of the inferior pole of the patella was marked on the skin using tape. The distance between medial displacement tape and the lateral displacement tape was measured by the researcher with a tape measure in millimeters and was recorded as the total displacement of the inferior pole of the patella in the coronal plane (Figure 1). Both pieces of tape were removed between tests. This was repeated five times, with a one-minute rest between each test. Then the contralateral leg was measured in the same manner. Usually in clinical practice, markings are made on the skin with a pen but tape was used in this study so that researcher had no visual clues from previous tests.

(Insert Figure 1 here)

\section{$\underline{\text { Statistical Analysis }}$}

Individuals with healthy knees: the mean (and standard deviation) patellar mobility was calculated for the first assessment of the 44 legs of the 22 participants with healthy knees. The difference in mean (95\% confidence intervals $(\mathrm{CI})$ ) between left and right legs and between dominant and non-dominant legs was calculated. For each of the other four repetitions, the mean value for that repetition and the average value of the means of the repetition and each preceding repetition were calculated. The intra-class correlations (ICC) between the first assessment and the average values were also calculated using SPSS statistical package version 23 (SPSS Inc, 
Chicago, IL) using average measures, absolute-agreement, 2-way mixed-effects model [16]. An ICC over 0.75 was indicative of an excellent correlation [17].

\section{Comparison with mean patellar mobility in PFP patients:}

Mean patellar mobility for the first assessment of the 22 participants with healthy knees were compared with the mean patellar mobility observed in the TIPPS study population overall and, then, with each of the three PFP subgroups identified in the TIPPS study [11]. In this latter study the test was only applied on one occasion using the same technique as described above with the exception that only the leg with PFP (or if bilateral, worst pain) was measured and skin marks were made with a pen.

As both legs on an individual with healthy knees were measured, there was potential for introducing a clustering effect, which would inflate the standard error of statistical tests, when comparing the mean values with those of the TIPPS study. Therefore,

Assuming that the mean patellar mobility in adults without PFP (healthy knees) was 
2016), we estimated we would need at least 40 knees (20 participants) to estimate to +/- $1.5 \mathrm{~mm}$ with $95 \%$ confidence. A sample of 20 healthy knee participants would allow a difference of at least $4.6 \mathrm{~mm}$ (the smallest difference between two TIPPS subgroups) to be detected between the healthy knee and PFP group taking into account the imbalance between the number of observations in the healthy knee and the TIPPS subgroups (smallest 1 to 1.45) for a $99 \%$ statistical significance (to allow for the Bonferroni Correction for 4 groups) and a study power of $80 \%$.

\section{Results}

Of the 22 participants, 13 (60\%) were female. The mean age was 26 years (SD 6.7), the mean weight was $71.2 \mathrm{~kg}$ (SD 13.9) and mean height $1.7 \mathrm{~m}$ (SD 0.09). This was similar to the TIPPS subgrouping study in which $66 \%$ were female, the mean age was 26 years (SD 5.6), the mean weight $73.5 \mathrm{~kg}$ (SD 18.3) and height $1.7 \mathrm{~m}$ (SD 0.11) (Selfe et al 2016).

Total medial-lateral patellar mobility in 44 healthy knees: The mean patellar mobility for the 44 healthy knees on first measurement was 15.9 (SD 5.0) $\mathrm{mm}$. There was no statistically significant difference in mean patellar mobility between the right and left leg $($ difference in mean $=0.6(\mathrm{SD} 3.8) \mathrm{mm}, 95 \% \mathrm{Cl}$ for difference in mean -1.1 to 2.3 $\mathrm{mm}$; t-test 0.729; df $21 ; \mathrm{P}=0.47$ ), and dominant and non-dominant side (difference in mean $=0.1(\mathrm{SD} 3.8) \mathrm{mm}, 95 \% \mathrm{Cl}$ for difference in mean -1.6 to 1.8 ; t-test $0.166 ; \mathrm{df}$ $21 ; P=0.87)$. The mean patellar mobility and the ICC appeared to be very stable over the multiple repetitions (Table 1). 
224 A comparison of healthy individuals with people with PFP: Following random selection of one knee from each participant with healthy knees, 14 right and 8 left healthy knees were available for comparison with the 127 knees from the PFP participants in the TIPPS study. The mean patellar mobility in the 22 randomly selected healthy knees was $16.4 \mathrm{~mm}$ (SD 5.3) and in those with PFP was $12.2 \mathrm{~mm}$ (SD 4.6) (table 2). This difference was statistically significant (difference in mean 4.2 (SD 4.9) $\mathrm{mm}, 95 \% \mathrm{Cl}$ for difference in mean -6.3 to $-2.0 \mathrm{~mm}$; $\mathrm{t}=-3.81$, df 1 , $P<0.001)$. When the data of the healthy knee group was compared to the three PFP subgroups, a significant difference was observed $(\mathrm{F}=22.48, \mathrm{P}<0.001)$, but pairwise comparisons showed that only the 'weak and tighter' $(P<0.001)$ and 'strong' subgroups $(\mathrm{P}<0.001)$ had significantly lower mean patella mobility (Table 2$)$. There were no significant difference in mean patellar mobility between the 'weak and pronated feet' PFP subgroup and the healthy knees group $(P=1.000)$ (Table 2).

Insert Table 2 and Figure 2 here

\section{Discussion}

We have, for the first time, provided normative data for the medial-lateral patellar glide test as measured in adults. Our findings are similar to those reported for adolescents (mean $16.0 \mathrm{~mm}$ ) using a similar technique [12]. However, our mean patellar mobility is considerably lower than what Witvrouw et al reported in a much larger sample of similar age [13]. In this study, though, medial and lateral mobility were performed separately and later added to calculate the total patellar mobility. 
247 This different execution might explain the difference between the values in the two studies.

Like Witvrouw, however, we did find a difference in mean scores between those with healthy knees and those with PFP overall [13]. When different PFP subgroups were considered participants allocated to the 'weak and tighter' and 'strong' subgroups were found to have significantly lower patellar mobility than healthy participants, which provides some evidence for patellar hypomobility in these subgroups. Those participants who fell into the 'weak and pronated feet' subgroup had a similar mean patellar mobility to the healthy knee group. This subgroup made up 39\% of the PFP participants in the TIPPS study, but were this prevalence higher in other PFP samples, it might explain why some studies have not found a difference between PFP and healthy knee groups [14]. More research needs to be conducted to understand patella mobility in the weak and pronated PFP subgroup as a possible explanation for the lack of difference could be the participants' position during the test. In standing, pronation of the feet will lead to an internal rotation of the tibia, which causes the patella to move medially [18]. This is turn can increase the contact mobility might not have occurred.

This study also suggests that a single measurement of the medial-lateral glide test as practiced routinely is sufficient. This has implications for clinical practice, as only 
one assessment will reduce the time required to be spent on clinical assessment.

272 The difference in mean patellar mobility across repetitions was minimal and the ICC remained above 0.9, well into the excellent range [17].

This study was not designed to measure the standard error of measurement (SEM), as there was not enough time between recordings on participants to reduce the risk of recall bias. This limits the interpretation of the differences between the PFP subgroups and those with healthy knees. However, if we were to assume no recall bias, then the SEM for healthy knees is $1.24 \mathrm{~mm}$ (when $S D^{*} \sqrt{ }(1-I C C)$ using the $1^{\text {st }}$ and $2^{\text {nd }}$ repetitions: see table 1) [19] and the minimal detectable change (MDC95) $3.4 \mathrm{~mm}$ (when $\mathrm{MDC}_{95}=1.96^{*} \mathrm{SEM}^{*} \sqrt{2}$ ) [20]. As the MDC is less than the difference between the healthy knees and the weak and tight PFP subgroup and the difference between the healthy knees and the strong PFP subgroup, if would suggest that these differences are real. Further research is needed to estimate the SEM under more optimal conditions in PFP patients to facilitate comparisons between subgroups, and to estimate other important measurement properties, such as, interrater reliability.

It might be argued that another important limitation of this study was the nonrandomization of the ordering of the test between left and right leg, but the mean patellar mobility was similar in the two legs. Data was lost because our approach to handling clustering was to randomly select one leg per healthy knee participant for comparison with the PFP group/subgroups. However, this was necessary to ensure 
consistency across groups as only one leg was measured in the TIPPS study, even when both knees were affected.

\section{Conclusion}

The total medial-lateral patellar mobility can be measured reliably in a one-off measurement using the patellar glide test. The mean patellar mobility of healthy adult participants was significantly different to the mean patellar mobility in participants with PFP and suggests hypomobility in at least two subgroups of people with PFP. This could help direct therapeutic intervention in these patients but further work is needed on the diagnostic properties of this test.

Acknowledgements

We would like to thank Arthritis Research UK for funding the subgrouping study on PFP patients (grant number 19950) ARUK) and the Erasmus Scheme for funding a European physiotherapist to work with our team on this project.

Ethical Approval: This study was approved by the University of Central Lancashire Science, Technology, Engineering, Medicine and Health ethics committee (STEMH 355). The PFP study (TIPPS) was approved by NRES Committee North WestGreater Manchester North, REC reference: 11/NW/0814 and University of Central Lancashire (UCLan) Built Sport and Health (BuSH) Ethics Committee Reference Number: BuSH 025. R\&D approval was also obtained from each participating NHS trust. 
318 Funding: Arthritis Research UK funded the subgrouping study on PFP patients (grant 319 number 19950), the Erasmus Scheme funded a European physiotherapist to work on 320 the normative data.

321

322 The authors declare no conflicts of Interest.

323

324

References

325

[1] van Dijk CN, van der Tempel WM. Patellofemoral pain syndrome. BMJ. 2008 Oct 24;337:a1948.

327

328

[2] Price AJ, Jones J, Allum R. Chronic traumatic anterior knee pain. Injury. 2000 Jun;31(5):373-8.

330

[3] Stathopulu E, Baildam E. Anterior knee pain: a long-term follow-up.

Rheumatology (Oxford). 2003 Feb;42(2):380-2.

333

[4] Rathleff MS, Rathleff CR, Olesen JL, Rasmussen S, Roos EM. Is Knee Pain

During Adolescence a Self-limiting Condition? Prognosis of Patellofemoral Pain and

Other Types of Knee Pain. Am J Sports Med. 2016 May;44(5):1165-71.

337

338

[5] Wyndow N, Collins N, Vicenzino B, Tucker K, Crossley K. Is There a

339

Biomechanical Link Between Patellofemoral Pain and Osteoarthritis? A Narrative

340 Review. Sports Med. 2016 Dec;46(12):1797-1808. 
[6] Powers CM, Witvrouw E, Davis IS, Crossley KM. Evidence-based framework for

a pathomechanical model of patellofemoral pain: 2017 patellofemoral pain consensus statement from the 4th International Patellofemoral Pain Research Retreat, Manchester, UK: part 3. Br J Sports Med. 2017 Dec;51(24):1713-1723.

[7] Lack S, Barton C, Sohan O, Crossley K, Morrissey D. Proximal muscle rehabilitation is effective for patellofemoral pain: a systematic review with metaanalysis. Br J Sports Med. 2015 Nov;49(21):1365-76.

[8] Rowlands BW, Brantingham JW. The efficacy of patella mobilization in patients suffering from patellofemoral pain syndrome. J Neuromusc Sys 1999:7(4), pp142-49.

[9] Barton CJ, Lack S, Hemmings S, Tufail S, Morrissey D. The 'Best Practice Guide to Conservative Management of Patellofemoral Pain': incorporating level 1 evidence with expert clinical reasoning. Br J Sports Med. 2015 Jul;49(14):923-34.

[10] Powers CM, Bolgla LA, Callaghan MJ, Collins N, Sheehan FT. Patellofemoral pain: proximal, distal, and local factors, 2nd International Research Retreat. J Orthop Sports Phys Ther. 2012 Jun;42(6):A1-54.

[11] Selfe J, Janssen J, Callaghan M, Witvrouw E, Sutton C, Richards J, Stokes M, 363 Martin D, Dixon J, Hogarth R, Baltzopoulos V, Ritchie E, Arden N, Dey P. Are there three main subgroups within the patellofemoral pain population? A detailed characterisation study of 127 patients to help develop targeted intervention (TIPPs). Br J Sports Med. 2016 Jul;50(14):873-80. 
368 [12] Skalley T, Terry G, Teitge R. The quantitative measurement of normal passive medial and lateral patellar motion limits. Am J Sports Med. 1993 23(5):728-732

371 [13] Witvrouw E, Lysens R, Bellemans J, Cambier D, Vanderstraeten G. Intrinsic risk 372 factors for the development of anterior knee pain in an athletic population. A twoyear prospective study. Am J Sports Med. 2000 Jul-Aug;28(4):480-9.

[14] Ota S, Nakashima T, Ayako Morisaka A, Ida K, Kawamura M. Comparison of

Patellar Mobility in Female Adults With and Without Patellofemoral Pain. J Orthop

Sports Phys Ther 2008 38(7):396-402

[15] Fithian DC, Mishra DK, Balen PF, Stone ML, Daniel DM. Instrumented

measurement of patellar mobility. Am J Sports Med. 1995 Sep-Oct;23(5):607-15.

[16] Shrout PE, Fleiss JL. Intraclass correlations: uses in assessing rater reliability. Psychol Bull 1979;86:420-8.

[17] Fleiss JL. The design and analysis of clinical experiments. New York: John Wiley \& Sons;1986.

[18] Curran SA. Chapter 10: The Use of Foot Orthoses in the Management of 
393 [19] Stratford PW. Getting more from the Literature: estimating the standard error of 394 measurement from reliability studies. Physiother Can 2004; 56: 27-30.

396 [20] de Vet HC, Terwee CB, Ostelo RW, Beckerman H, Knol DL, Bouter LM. Minimal 397 changes in health status questionnaires: distinction between minimally detectable 398 change and minimally important change. Health Qual Life Outcomes. 2006 Aug $39922 ; 4: 54$. 
400 Table 1: Stability of the data from the total medial-lateral patellar glide test in healthy 401 knees $(n=44)$

\begin{tabular}{|c|c|c|c|c|c|}
\hline & \multicolumn{5}{|c|}{ Repetition } \\
\hline & 1 & 2 & 3 & 4 & 5 \\
\hline Mean in $\mathrm{mm}$ & $\begin{array}{l}15.9 \\
\text { (SD 5.0) }\end{array}$ & $\begin{array}{l}15.9 \\
(S D 4.4)\end{array}$ & $\begin{array}{l}15.8 \\
(S D \text { 4.2) }\end{array}$ & $\begin{array}{l}15.8 \\
(S D 4.5)\end{array}$ & $\begin{array}{l}15.8 \\
(S D 4.4)\end{array}$ \\
\hline $\begin{array}{l}\text { Average of mean } \\
\text { over repetitions in } \\
\mathrm{mm}\end{array}$ & $n / a$ & $\begin{array}{l}15.91 \\
(S D 4.69)\end{array}$ & $\begin{array}{l}15.89 \\
\text { (SD 4.51) }\end{array}$ & $\begin{array}{l}15.87 \\
(\mathrm{SD} 4.50)\end{array}$ & $\begin{array}{l}15.85 \\
(\mathrm{SD} 4.46)\end{array}$ \\
\hline $\operatorname{ICC}(\mathrm{Cl})^{*}$ & $n / a$ & $\begin{array}{l}0.93 \\
(0.86-0.96)\end{array}$ & $\begin{array}{l}0.95 \\
(0.90-0.97)\end{array}$ & $\begin{array}{l}0.95 \\
(0.90-0.97)\end{array}$ & $\begin{array}{l}0.94 \\
(0.88-0.97)\end{array}$ \\
\hline
\end{tabular}

402 Abbreviations: $\mathrm{mm}=$ millimeters, $\mathrm{SD}=$ standard deviation, $\mathrm{ICC}=$ intra-class correlation

403 coefficient, $\mathrm{Cl}=95 \%$ confidence interval $\mathrm{n} / \mathrm{a}=$ not applicable, ${ }^{*} 1^{\text {st }}$ compared to 404 average of repetitions 
Table 2: Comparison of mean patellar mobility between healthy and PFP knees

\begin{tabular}{|c|c|c|c|}
\hline & $\begin{array}{l}\text { Mean (SD) patellar } \\
\text { mobility in mm and } \\
\qquad 95 \% \mathrm{Cl}\end{array}$ & $\begin{array}{c}\text { Difference in mean }(\mathrm{mm}) \text { between } \\
\text { healthy knees group and PFP subgroup } \\
(95 \% \mathrm{Cl} \text { difference in mean })\end{array}$ & $\begin{array}{c}\text { Pairwise } \\
\text { comparison } \\
\text { (p value) }\end{array}$ \\
\hline $\begin{array}{l}\text { Healthy Knees } \\
(\mathrm{N}=22)^{+}\end{array}$ & $\begin{array}{c}16.4(5.3) \\
14.0-18.7\end{array}$ & & --------- \\
\hline $\begin{array}{l}\text { PFP subgroup- } \\
\text { weak and tighter } \\
(\mathrm{N}=49)\end{array}$ & $\begin{array}{c}9.9(3.6) \\
8.9-10.9\end{array}$ & $\begin{array}{c}-6.5^{\star} \\
(-9.3 \text { to }-3.7)\end{array}$ & $<0.001$ \\
\hline $\begin{array}{l}\text { PFP subgroup - } \\
\text { weak and } \\
\text { pronated }(\mathrm{N}=49)\end{array}$ & $\begin{array}{c}15.4(4.6) \\
14.1-16.7\end{array}$ & $\begin{array}{c}-1.0 \\
(-3.8 \text { to } 1.9)\end{array}$ & 1.000 \\
\hline $\begin{array}{l}\text { PFP subgroup - } \\
\text { strong }(\mathrm{N}=29)\end{array}$ & $\begin{array}{l}10.8(3.0) \\
9.6-11.9\end{array}$ & $\begin{array}{c}-5.6 \\
(-8.7 \text { to }-2.5)\end{array}$ & $<0.001$ \\
\hline
\end{tabular}

Abbreviations: $\mathrm{N}=$ number of participants in the group, $\mathrm{mm}=$ millimeters, $\mathrm{SD}=$ standard deviation, ${ }^{+}$one leg was randomly chosen, $\mathrm{Cl}=$ confidence interval . 
Figures

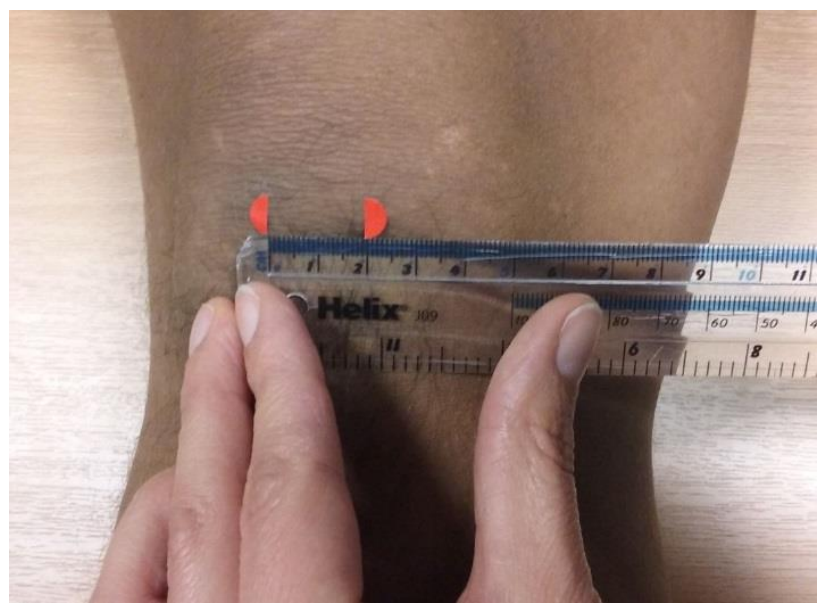

Figure 1: the total medial-lateral patellar glide test with markings on the skin 


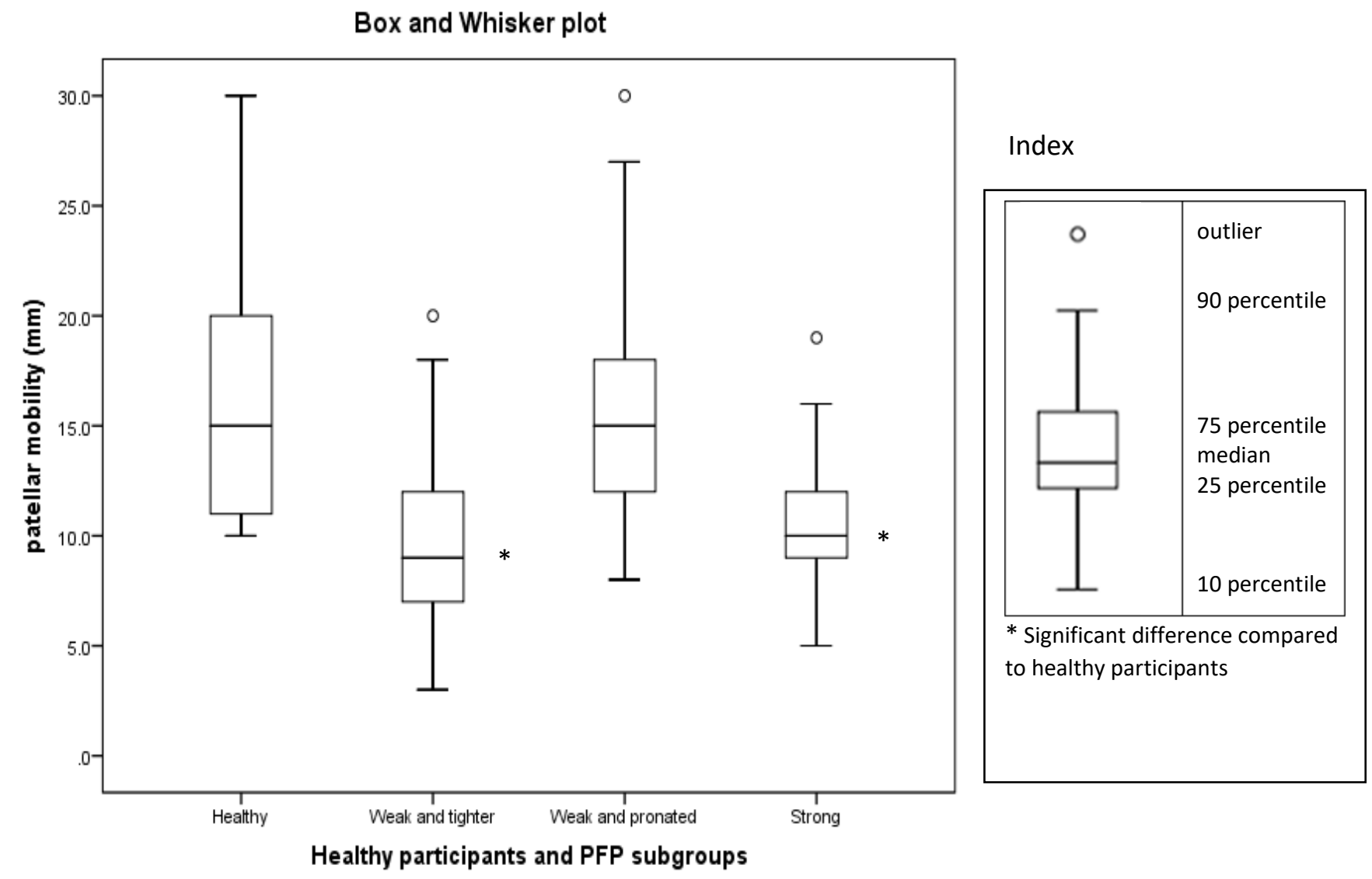

Figure 2: Box and Whisker plot for healthy participants and participants allocated to the three PFP subgroups. 